\title{
AÇÃO E EXPERIÊNCIA NOS ESPORTES COLETIVOS
}

\section{Eduardo Fernandes Nazareth}

DOI: http//dx.doi.org/10.17666/308759-77/2015

\section{Introduçáo}

O objetivo deste artigo é esboçar as bases para uma microssociologia do esporte voltada ao que consideramos ser seu fenômeno mais central, o jogo, especialmente o jogo esportivo coletivo. Pretende-se oferecer uma opção em termos teóricos para lidar com o tema esportivo. Trata-se da construção de uma alternativa teórica ao olhar estrutural que frequentemente os estudos sociológicos, fundados na sociologia configuracional de Norbert Elias ou no estruturalismo construtivista de Pierre Bourdieu, lançam sobre o esporte.

Acreditamos que, a partir da obra de autores ligados a outras escolas de pensamento, como a fenomenologia, o pragmatismo e seus rebentos sociológicos, a etnometodologia e o interacionismo simbólico - cujos autores mais reconhecidos são,

Artigo recebido em 18/12/2013

Aprovado em 24/09/2014 respectivamente, Garfinkel e Goffman -, e mesmo que esses grandes nomes não tenham se debruçado especificamente sobre o tema do esporte, tendo-se em mente a própria perspectiva teórica que propuseram ao abordarem o jogo, ${ }^{1}$ podemos, ao articulá-los, adquirir uma compreensão mais sólida e profunda acerca de certos aspectos microssociológicos do fenômeno esportivo sobre os quais a obra de Elias e de Bourdieu não nos possibilita avançar muito.

Desse modo, pretende-se neste artigo, a partir de um olhar microssociológico apoiado sobre referências teóricas fenomenológicas e pragmáticas, compreender o fenômeno do jogo esportivo especialmente do jogo esportivo coletivo-abordando-o como experiência efetivamente vivida pelos praticantes, isto é, como uma experiência prática intersubjetiva, íntegra e total, que em seu enquadramento e organizaçáo envolve e interliga o outro, o corpo, os objetos, o espaço e o tempo, com um sentido intenso de vida. Voltamos o olhar para uma diversidade 
de aspectos práticos fundamentais à constituição da realidade do jogo e ao tipo de experiência que ele é capaz de proporcionar entre os jogadores.

Partimos do princípio de que o modo com que as ações se ordenam em uma disputa é sustentado pela organização da atividade coletiva própria dos jogos; esta é que, em última instância, torna a experiência de jogar uma experiência excepcional. O jogo é uma atividade prática cuja organização é o que lhe confere suas características mais essenciais e distintivas. Os traços de complementaridade e mútua referencialidade entre as açóes, a circularidade lógica e a progressividade temporal de todo o complexo interativo, apoiados em um núcleo de disputa capaz de aderir toda a atenção e as energias ao aqui e agora, geram uma zona intersubjetiva de grande poder de atração, tornando a atividade envolvente e arrebatadora. É justamente aqui, nessa organização transcendental, do ponto de vista do praticante, que reside aquilo que mais propriamente chamamos jogo.

É importante nessa perspectiva ter em mente que as dimensóes fundamentais dessa experiência geralmente abordadas de maneira compartimentada por especialistas de uma ou outra área de conhecimento (a fisiologia, a medicina esportiva, a psicologia, a tática e a estratégia, entre outras) - se articulam como parte da totalidade de um mesmo fenômeno social: a experiência coletiva de jogar. Visamos restituir e reafirmar tal totalidade, pois com base nela se extrai o sentido pleno obtido pelo jogo como experiência coletiva intersubjetiva.

Para uma ideia mais concreta do modo como essa outra realidade se apresenta e do que consideramos ser o centro do fenômeno jogo, basta nos remetermos à cena bastante comum de meninos jogando futebol em uma rua de subúrbio ou em um campinho qualquer. É notável o alto poder de absorção dessa atividade; e para o olhar menos naturalizado, é impressionante como a dinâmica os mantém completamente imersos na experiência de jogar até o fim da partida.

Pretendemos mostrar aqui como o jogo é capaz de obter dos jogadores tal adesão, que se dá em um mesmo enquadramento, a partir de uma inserção existencial particular, o que implica um lançar-se na mesma atividade em um modo de ser incorporado e espacializado; atividade essa cuja lógica prática sus- tenta e aprofunda a atenção nessa zona de experiência comum, tornando-nos inteiramente concentrados nela - isto é, concentrados em nós mesmos no curso de nossa ação coletiva, em nosso movimento e totalmente alheios ao que se passa fora do campo. ${ }^{2}$ Adentramos, pois, essa zona intersubjetiva inaugurada com o início do jogo para compreender como essa dinâmica da prática - uma estrutura concreta, presente na ordenação endógena das açóes reais se sustenta, dando sentido à experiência vivenciada em comum pelos jogadores.

Não se pode deixar de ter em mente que há aqui também um conjunto de elementos físicos (bola, traves, redes etc.) constitutivos de um ambiente organizado em relação à lógica da prática competitiva que, engrenados à ação e concorrendo por gerar um desafio coletivo, produzem durante a partida o efeito de atrair, aderir, envolver e interligar a todos nessa zona intersubjetiva que, em função da lógica mesma de competição, em relação com os corpos, pode avançar no tempo imanente comum de uma corrente total e temporal de eventos plena de um sentido evidente, corrente essa continuamente produzida e percebida na prática pelos próprios jogadores.

No caso dos jogos esportivos, trata-se de uma lógica que podemos resumir, a princípio, de forma simples: uma disputa entre duas equipes que ocorre em interaçôes conduzidas pelos jogadores em açóes simultâneas e mutuamente orientadas, envolvendo o corpo em torno da condução coletiva de um objeto (geralmente uma bola) a uma meta bem delimitada. As duas equipes alternam-se na tarefa de tentar alcançar essa meta e de tentar impedir o oponente de alcançá-la; ora uma equipe ataca (quando conquista a posse da bola) enquanto a outra defende; ora esta ataca enquanto a primeira defende - a ordem interativa do jogo define os termos dessa alternância. Já que vence aquela que alcançar mais vezes a meta, a dinâmica gerada requer que o façam engajando suas energias ao máximo, tanto na defesa quanto no ataque, acirrando-se a disputa a cada lance por todo o tempo da partida. Buscaremos compreender como essa estrutura lógica fundamental permite se produzir uma experiência envolvente, arrebatadora e total (como os próprios praticantes a ela comumente se referem). 


\section{Que experiência é essa a de jogar?}

A experiência viva do mundo transcorre em uma corrente temporal pré-empírica (Husserl, 1959, p. 170), unidirecional e progressiva (Schutz, 1979, p. 61), sendo factualmente preenchida de acordo com a ordem ontológica da ocupaçáo assumida que define um modo de ser (Heidegger, 2005, pp. 9495). Viver é experimentar a si mesmo na experiência do mundo, do qual eu, o outro e os objetos fazemos parte no ambiente e no tempo presente, a partir de modos inter-relacionados e codeterminados de ser, isto é, com base em uma ontologia constitutiva de um mundo circundante de existência pré-fenomenal a ser vivido agora em uma ocupação real (Idem, pp. 108-109).

No caso dos jogos agonísticos - jogos esportivos coletivos -, a experiência consiste em uma atividade prática dotada de caráter desafiador, cuja lógica se mostra capaz de arrebatar todo o ser na forma de um ser jogador em uma ordem de atividade própria do mundo do jogo. Esse ser organiza-se em relação à totalidade do desafio, em função do qual se estabelece um eixo espaço-temporal entre o ponto de partida e o objetivo, zona intermediada e organizada pelos meios lógicos possíveis, dentro das regras, de alcançá-lo, exigindo intensa mobilização de energia. Isto é, todo o conjunto prático em que o jogador se insere implica uma estrutura existencial que se apresenta em relação a um mundo, aos objetos e espaços e à sua ordem ontológica presente como constituinte da facticidade da experiência de jogar (Idem, p. 95).

Por um lado, na superação do desafio total que os indivíduos assumem diante do que o mundo circundante lhes apresenta, eles se dispóem a se lançar integralmente. Por outro, a existência transcorre no tempo arrebatada por uma dinâmica competitiva contínua e progressiva que, mobilizando emoçóes, corpos, percepções e a cognição no espaço em situaçóes desencadeadas pelo pontilhado lógico transcendental da forma do jogo, requer certa ordenação da atenção e de fluxos e retençóes coordenados de energia no tempo imanente da experiência prática do jogar. $\mathrm{O}$ jogo, desse modo, ordena a existência de todos, fazendo fundir interior e exterior em uma mesma zona intersubjetiva arrebatadora de experiência coletiva.
Apresenta-se ali uma relação singular de totalidade do ser jogador - todos propriamente são uns com e contra os outros, e uma mesma corrente de eventos que se sucede ininterruptamente.

Portanto, na experiência de jogar ocorrem, em termos heideggerianos, uma concentração e um alinhamento do ser com o mundo, no nosso caso, do jogo. Trata-se, como diria Dewey (1974, p. 249), de uma experiência prática bem integrada e ordenada, distinta e marcante, dotada de características estéticas de delimitação, proporção, ritmo e harmonia. Veremos ao longo deste artigo como o jogo propicia tal experiência e quais suas características.

\section{O que caracteriza a experiência esportiva?}

$\mathrm{O}$ que fundamentalmente caracteriza uma experiência esportiva? A prática esportiva exige de quem se dispóe a jogar que, a partir do modo impessoal de ser jogador, encontre um modo próprio de lidar com os desafios que o jogo apresenta. Em função da organização - da prática competitiva e (caso haja) de experiências anteriores já sedimentadas, esse modo mais pessoal de ser jogador se vê em uma imersão ativa num mundo que então se coloca entre nós competidores e que se mostra profundamente desafiador. Trata-se de uma ordem de existência repleta de elementos pré-reflexivos, propensa a uma abertura e a um aprofundamento existencial no que os psicólogos do esporte chamam de the zone: região da experiência aberta por um modo comum de vivenciar o jogo, predisposta ao que um dos mais influentes entre eles, Mihaly Csikszentmihalyi (2008) (embora não se possa dizer que seu trabalho se refira apenas ao campo esportivo) chama de experiência de fluxo (flow).

O fluxo resulta de experiências em práticas que produzem grande satisfação por consistir em densa experiência ordenadora e desencadear um sentido profundo de unificação entre interior e exterior. Tal integração no curso da atividade só se dá por haver correspondência entre a prática e a competência previamente adquirida, então mobilizada em uma situação real que, desse modo, se mostra desafiadora.

O contexto real, que demanda uma ação de acordo com a forma prática requerida e evoca uma 
estrutura existencial determinada, impulsiona o ser ao pleno exercício de suas potencialidades mais próprias, resultando, no caso dos jogos esportivos, em uma experiência sensivelmente autêntica de ser a si mesmo.

Poderíamos assim dizer que, ao propiciar uma apropriação do ser jogador, a princípio, impessoal e adequando-se às determinações pré-pessoais da atividade, possibilita-se na atividade viva a experiência plena de si na integração com o mundo esportivo circundante por meio de uma atividade prática autêntica, própria, que apresenta um sentido de totalidade e de realização. ${ }^{3}$

Para Csikszentmihalyi, a experiência de fluxo possui características mais específicas que, no nosso entender, em relação ao esporte, expressariam o sentido de integração e de totalidade entre ser e mundo por meio da prática, isto é, pelo exercício de uma competência em sua máxima capacidade, conferindo à experiência o sentido táo propalado por praticantes de arrebatamento e de plenitude a que o autor se refere.

Em síntese, a experiência de fluxo é geralmente obtida em práticas que apresentam objetivos claros e imersos em uma ordem prático-ontológica configurada de tal modo que o agente perceba certo equilíbrio entre o nível da dificuldade e suas capacidades, pois é daí que nasce o desafio, o ressaltar de um sentido de potência e a tendência a uma profunda mobilização interior.

Em função dos objetivos propostos e dos meios disponíveis, determinam-se as condiçóes de direcionamento para que o ser se oriente e capture ao redor os dados relevantes, que então, ordenados sob a lógica do jogo, como feedbacks, retroalimentam continuamente a corrente de experiência, impulsionando-a adiante de maneira organizada e contextualizada, num tempo interior fluido e imanente à própria prática concreta, alcançando-se aquele estado de profunda concentração na sequência contínua de tarefas.

A lógica da atividade, em correlação com uma competência própria mais ou menos especializada, contribui desse modo por dispor e organizar o mundo ao redor de modo a alimentar um impulso prospectivo à continuidade no fluxo da ação, sustentada pelo sentido desafiador constante dado pelo equilíbrio entre o nível da habilidade e da di- ficuldade gerado pela forma do desafio. Imerso na sequência bem encadeada de tarefas e diante do impulso inercial obtido na sucessão de situaçóes que emergem prospectivamente da lógica da disputa, forma-se no espaço e no tempo vividos em comum quase que uma só corrente prática demarcada por alguns pontos de inflexão no seu interior determinados por tal lógica. Outro ser, prático, nasce e vigora na ocupação, predispondo-se a entradas no fluxo.

A experiência, inteiramente voltada à sucessão de tarefas à mão, tende a fechar-se à entrada de dados irrelevantes e potencialmente desorganizadores. A preocupação com o "eu" ou com a autoimagem, por exemplo, reduz-se significativamente, pois se vive, na maior parte do tempo, em um estado de imersão da consciência na ação ou em preparação para ela, conforme as tarefas que se colocam no mundo circundante. A experiência tende a se encerrar na própria continuidade entre a ação e o seu fim imediato, o que representa outro de seus traços distintivos: ela é autotélica, ou seja, não se motiva propriamente por fins exteriores (ou expectativas exotélicas), mas pelo sentido profundo dado pela pretensão de intervenção no mundo ao redor.

No caso dos esportes coletivos, vale observar que o sentido autotélico dessas experiências, que Csikszentmihalyi concebe em temos individuais, converge a um sentido coletivo. É preciso considerar que os esportes coletivos geram metas que só podem ser alcançadas coletivamente. Seus desafios impóem a necessidade da convergência solidária, da referência mútua e da coordenação entre as açóes e as experiências em relação a uma meta. Por isso, as correntes individuais de experiência sob a lógica do jogo se enfeixam e se interpenetram no tempo e no espaço sob uma mesma organização, conformando uma corrente total e desafiadora de eventos vividos, entretanto, de ângulos diferentes. As correntes individuais de experiência estão sob a mesma ordenação da forma de disputa do jogo e são referidas às mesmas formas de ação, permitindo aos membros competentes da comunidade de praticantes identificar o sentido fino do que se passa entre nós e as determinaçóes circunstanciais de cada jogada. Tais correntes estão fundadas sobre as mesmas expectativas de desdobramento do desafio. Dessa forma, sendo mantidas sob o mesmo enquadramento ao longo de toda 
a partida, elas se retroalimentam pelos mesmos feedbacks que, produzidos e percebidos coletivamente, impulsionam nossa disputa. Assim, podemos acrescentar que, nos esportes coletivos, essas experiências além de autotélicas são também sociotélicas.

Para melhor compreendermos o caráter sociotélico dos jogos esportivos coletivos, vale observar que, enquanto jogamos, estamos em uma zona intersubjetiva que se conforma a partir do intercâmbio de pontos de vista entre os jogadores e da congruência do sistema de relevância (Schutz, 1967b, pp. 11-12) do jogo em questão. Assim, enquanto se joga, num nível constitutivo mais fundamental, pressupondo-se o domínio das competências básicas acerca de como jogar, dou como certo que sei o que você sabe e como você deverá agir, que você sabe vagamente o que eu sei e como deverei agir, que todos sabemos que todos sabem minimamente como jogar, e nesse sentido confiamos uns nos outros (Garfinkel, 1963). Desse modo, as bases de tal zona intersubjetiva se estabelecem. Sobre ela as experiências de cada participante avançam no tempo total e comum de uma partida a partir de uma perspectiva própria, referindo-se, entrecruzando-se, condicionando-se umas às outras no curso das jogadas; enfim, impregnando-se das impressóes deixadas pelos eventos percebidos em sua identidade típica, testemunhados quase que simultaneamente (Schutz, 1964; 1967a, pp. 102-107), e que, como feedbacks compartilhados, oferecem sentidos mais ou menos evidentes segundo as demarcaçóes lógicas próprias do jogo, dadas por formas naturalizadas de ação que tornam inteligível e até evidente ao jogador minimamente competente o que se passa ao redor. Tudo constituindo a fluência de uma mesma corrente de eventos produzida e vivenciada por todos os jogadores aqui e agora, onde os eventos a seguir são produzidos, preservando assim seu sentido de participação viva, de adesão e de totalidade.

É aqui, nessa zona intersubjetiva, que a partida é vivenciada pelos jogadores, diferentemente do torcedor ou do comentarista. Apenas os jogadores estão submetidos ao campo de forças entre seus corpos; só eles estão sob a influência de seus efeitos; só eles vivenciam o jogo de dentro dessa zona intersubjetiva assentada no campo de jogo, intervindo diretamente sobre a sucessão dos eventos.

\section{Especificando a questáo e o método}

Como essas experiências se produzem em esportes coletivos como basquetebol, futebol, voleibol, handebol, rúgbi e muitos outros? Como é possível que nós jogadores compartilhemos uma mesma atividade no interior da qual nos coordenamos? Como ela se sustenta em um tempo e espaço intersubjetivos e sob uma mesma ordem, mantendo-nos atraídos ao centro de uma disputa, em uma zona de experiência no agora sob uma ordem interativa e relacional competitiva do início ao fim do jogo? As respostas a essas questóes nos conduzem à análise da estrutura formal dessa prática, tendo em mente as relaçóes daí decorrentes. É ela que, por exemplo, determina o sentido potencialmente decisivo da ação no presente instante, daqui até o fim da partida.

Além das características já mencionadas, os jogos esportivos em questão possuem, como forma prática, traços fundamentais de convergência: as tarefas formalmente definidas, que compóem os desafios para cada jogador, submetem-se e unificam-se em relação a uma meta coletiva a que se refere a totalidade temporal da partida. Esse é um traço estrutural dessa prática. No caso específico dos jogos esportivos coletivos, essas tarefas são organizadas para que as açóes sejam realizadas por todos os integrantes das duas equipes simultaneamente, em copresença, de modo interdependente, mutuamente referido, contínuo, unificado em seu desdobramento e finalidade. Trata-se de esportes em que cada membro da equipe deve concorrer para a realização de uma só ação coletiva em face da meta proposta pelo jogo contra a ação de um adversário, ambos podendo interferir na ação do outro a todo tempo dentro das restrições regulamentares constitutivas do desafio. Trata-se de feedbacks recíprocos e coletivamente perceptíveis que sustentarão a própria organização contínua da experiência prática no tempo e no espaço como uma ação nossa em curso contra a ação deles.

Não nos referimos a jogos como beisebol ou o cricket, cuja forma de disputa não permite uma interferência mútua tão aberta, simultânea e contínua da ação. Nesses esportes, após um início de contato mais direto entre lançador e rebatedor, as ações co- 
letivas das duas equipes seguem quase paralelas até o final, uma equipe não pode intervir diretamente sobre a ação da outra. A interação entre oponentes transcorre a partir das açóes da própria equipe em relação às da adversária, nunca a partir de uma intervenção direta. A concentração fundamental das energias e da atenção é predominantemente sobre a ação da própria equipe. Os esportes em questão neste trabalho se distinguem por possibilitar uma ação de intervenção direta e contínua entre todos (exceção parcial feita ao voleibol).

De modo geral, a convergência e a coordenação das açóes são parte do desafio a que deverão corresponder certas habilidades. $\mathrm{O}$ fato de essa atividade se desdobrar no tempo imediato do agora, simultaneamente, em copresença com os demais jogadores e ser, além de cooperativa e interdependente, marcadamente corporal impóe que as consciências localizem o acento constitutivo dos eventos no espaço ao redor, tornando-se extremamente incorporadas e espacializadas em um modo particular de ser jogador. As existências então se dispóem a se entrelaçar, voltadas para o interior desse espaço intersubjetivo, intercorporal, delimitado por nosso desafio, orientando-nos pelo sentido lógico e convergente que o jogo, em sua forma, cria para as açóes.

Mas como essa forma competitiva básica atua nas diversas dimensóes cognitivas, do imediato ao tempo mais alargado, possibilitando a criação de uma realidade própria da competição? Nesse sistema, duas dimensóes encontram-se inter-relacionadas e unificadas no ato de jogar. Ambas estão condicionadas pela experiência de todos os participantes, resultado da organização desse sistema competitivo em estado potencial nos esquemas mentais e corporais dos jogadores. Seu caráter de fechamento, auto-organização e autorreferência é o que gera uma atividade única, relativamente isolada da realidade exterior.

Diante dessa perspectiva, é fundamental compreender como os elementos do jogo estão predispostos a se interligarem em um mundo de existência social compartilhada e como são ativados e mobilizados a partir de uma atitude competitiva correspondente no momento real da partida, produzindo assim, prospectivamente, na ação individual e coletiva (dado o domínio da competência de jogar), sob a ordem típica do jogo (uma forma lógica), a competição concreta, os eventos - enfim, a partida. É dentro de uma ordem interativa fundamental que o resultado deve gradualmente emergir da dinâmica real das disputas da partida concreta, determinando-se no seu curso uma ordem na relação competitiva - quem está na frente ou atrás no placar, quem está jogando melhor ou pior -, descrevendo-se oscilaçóes, tensóes, incertezas, até o fim do jogo, quando se define um vencedor e um perdedor.

\section{Características fundamentais do jogo esportivo}

Não haveria uma gramática profunda dos jogos esportivos coletivos norteando a constituição formal de sua prática? Uma gramática que ordenaria nossa interação competitiva, capaz de nos predispor, sob sua ordem de atividade, a vivermos a ambiência própria às experiências de fluxo justamente por gerar e sustentar um impulso arrebatador a um alinhamento pessoal com esse nosso desafio coletivo real que então se forma temporalmente adiante e espacialmente ao redor de nós do início ao fim do jogo.

Vimos que, em sua forma básica, o jogo impele os jogadores, espontânea e continuamente, à ação, mas a uma ação de sentido e realização coletivos; ao mesmo tempo, cada jogador, individualmente, segue interferindo sobre e sofrendo os efeitos da ação de todos os demais em um mesmo complexo interativo. Essa ordem possui, como adiantamos, duas dimensóes: uma no plano interativo imediato e outra no plano das posiçóes que eles ocupam na relação competitiva. Ambas, no modo como se encontram relacionadas na constituição fundamental do jogo, dão movimento à partida como um todo.

Nesse movimento temporal progressivo, dotado de duas dimensôes inter-relacionadas na constituição da experiência de jogar - uma predominantemente espacial e outra temporal -, permanece atuante uma prática competitiva que mantém o ser em um meio termo oscilante e sempre parcial entre o possuir e o perder as condiçóes de controlar os eventos, visando superar o desafio maior de toda a partida, vencê-la. É justamente desse equilíbrio uma espécie de divisão formal entre as equipes que resulta o caráter absorvente da disputa, ao sus- 
tentar o engajamento na tarefa de controlar e orientar o sentido dos eventos. Assim, esse equilíbrio gera e atualiza o impulso entre os jogadores a lançar-se existencialmente por completo em uma dinâmica competitiva exterior, conservando-se a força desse mundo para impelir uns solidariamente contra os outros, obtendo deles o engajamento convergente de todas as suas habilidades e competências no tempo e no espaço do aqui e do agora para conduzir a relação no sentido da própria vitória.

Apenas diante de tal ordenação é que os jogadores são mobilizados espontaneamente e, de fato, se alinham com esse movimento exterior, que preenche todo o campo de consciência (Gurwitsch, 1957), sendo a um só tempo seu e dos demais jogadores. A lógica desse movimento já se organiza de maneira a produzir uma força centrípeta de envolvimento intersubjetivo integral sobre os jogadores na partida, gerando e sustentando, ao longo da competição, o impulso à superposição e à síntese entre a experiência interior e o mundo circundante zona existencial comum, congruente, arrebatadora, na qual aprofundamos nosso ser em razão da dinâmica da atividade. Para que isso seja possível, os movimentos ao redor de cada jogador, gerados pelo jogo nesse plano transcendental, devem ser ordenados, em sua totalidade, de maneira a se tornarem potencialmente atraentes porque capazes de comportar uma ação transformadora efetiva em torno da disputa, em especial no que se refere ao objetivo coletivo da equipe. Ou seja, devem incorporar, em algum nível, o poder de definição do encontro.

\section{Geração e organização de uma zona de disputa envolvente}

Para entender como uma só linha total de eventos faz convergir e galvanizar as açóes e as energias constituindo a corrente de eventos de uma partida, devemos partir da forma lógica básica das disputas, que demarca o que chamo de unidades interativas. É no interior delas que as disputas se conformam e se desdobram, determinando o sentido mais específico a uma mesma vontade e ação coletivas.

Geralmente as unidades interativas configuram-se da seguinte maneira: defesa A versus ataque B / perda da bola por B [transição] / ataque A versus defesa B... Cada perda de bola que redunde na posse da outra equipe demarca o fim de uma unidade interativa e o começo de outra, em um mesmo fluxo, com o ponto de inflexão da troca de papeis entre as equipes com a perda da bola daquela que até então a detinha: quem defendia agora ataca e quem atacava agora defende. As unidades interativas demarcam, fundamentalmente, o curso da nossa experiência.

Mas devemos voltar o olhar para dentro da unidade interativa, a fim de compreender como ela e a experiência de seus participantes, prospectivamente, se desdobram no tempo e no espaço comuns em quase simultaneidade. Para isso, é preciso dirigir ainda mais esse olhar para o núcleo gerador de toda a disputa, que basicamente se estrutura pelo embate entre atacantes e defensores pela posse da bola e/ ou pela direção a ser dada a ela. De um lado, um jogador busca conduzir a bola à meta, ajudado pelos companheiros, no sentido de dar continuidade à ação coletiva; de outro, a equipe adversária tenta obstruí-lo a fim de interromper a ação ofensiva e, se possível, retomar a bola (dentro do que a regra permite), para então alcançar sua meta, a ser defendida agora pelo oponente, que até o momento atacava. Sob essa lógica, em contínua atualização, todos se veem interligados na mesma unidade interativa e prontos a adentrar a seguinte como parte de uma equipe, em um só movimento imanente, progressivo e organizado. Lógica essa ordenada de tal modo que nenhum jogador, a despeito do engajamento de todas as energias e de toda a sua competência, possa controlar completamente os lances, colocando-se entre os competidores um problema desafiador de caráter coletivo, cuja solução deve envolver a todos, uns por e contra os outros, simultaneamente.

Assim, a unidade interativa acaba por nascer e se desenvolver em relação a um núcleo de disputa mais central em torno da bola, que ordena todas as demais interações, e por outros núcleos potenciais. De seu raio, a partir de sua posiçãa condicionante mais fundamental, produzem-se informaçóes que repercutem continuamente (como feedbacks) sobre núcleos menos centrais ou periféricos. Estes, por sua vez, também ordenam o núcleo central, pois lhes oferecem o sentido e as condições para a ação coletiva prosseguir no tempo e no espaço. É necessário que haja solidariedade e coordenação entre os 
jogadores para que a ação coletiva possa evoluir. $\mathrm{O}$ que ocorre é que diversas partes funcionais assumem posiçóes mais centrais ou mais periféricas ao longo da interação, dependendo das necessidades típicas da ação coletiva no esporte em questão e do desdobrar da disputa como um todo. Das disputas sob esse formato, ganha movimento o complexo interativo que então se constitui entre o conjunto de jogadores. E esse todo transita sobre o campo de jogo entre as metas, em avanços e recuos resultantes dessas disputas. Enfim, formando uma disputa como uma só totalidade espacial composta de movimentos interdependentes, solidários ou contrapostos, constitui-se, no formato descrito, uma mesma linha temporal de eventos cambiantes, condicionados a esse núcleo mais central em torno da bola.

No âmbito de cada forma de disputa que identifica um esporte, surgem diversas configurações, em si, formas menores que inter-relacionam açóes de atacantes e defensores, um ou mais núcleos de disputa, em totalidades práticas mais ou menos reconhecíveis entre os jogadores. Trata-se de formas presentes na constituição de uma experiência prática de percepção da jogada em curso, de concepção e realização das ações individuais correspondentes, de modo complementar e sistêmico, como parte de açôes coletivas tipicamente identificadas, presentes em esquemas mentais e corporais de jogadores. Elas possibilitam que a jogada em curso vigore intersubjetivamente, ordenando a própria coordenação ao vivo entre as açóes tanto de atacantes quanto de defensores. São exemplos: dismico, no voleibol, overlapping, no futebol, e pick and roll, no basquetebol.

Essas formas sociais de ação coletiva vigoram como gestalten, por meio das quais os eventos são percebidos pelos jogadores retroalimentando o próprio sentido de seus esforços e a produção endógena real da jogada, com suas lógicas e limites próprios, permitindo a ordenação do quê e como fazer a respeito da apreensão imediata do que se passa, englobando objetos, o próprio corpo e o dos demais, em conjuntos sintéticos e mais ou menos totais de movimento (Merleau-Ponty, 1999, p. 145) orientando, sob a lógica (de fundo) do jogo, o encaminhamento coletivo e mutuamente inteligível das açôes. Assim, essas formas possibilitam que os dados percebidos sejam demarcados em unidades e inter-relações típicas, supostamente as mesmas entre os jogadores de um mesmo nível ou da mesma comunidade, formando de dentro da nossa ação a identificação imediata do que se passa em sínteses perceptivas unificantes referidas a tais formas, apresentando-se factualmente suas conexôes prévias de sentido.

Diante da ação dessas formas organizadoras e constituintes, no transcorrer da disputa o experimentado se apresenta imediatamente em unidades identificáveis e simultânea ou sucessivamente distintas, criando continuidades e descontinuidades factuais imediatamente inteligíveis na experiência coletiva, produzindo demarcações em espaço-temporais sobre uma continuidade maior de fundo, a da totalidade da própria partida.

Mas não se pode deixar de considerar que se, por um lado, elas organizam o preenchimento da corrente temporal pré-empírica com eventos dotados de delimitaçóes e relaçóes previamente estabelecidas em um plano formal subjetivado, por outro, elas só atuam a partir de atos intencionais constituintes e prospectivos por parte da consciência do jogador - protensóes, reproduçôes, sínteses monotéticas, politéticas etc., em meio à retenção do percebido (Husserl, 1959); atos intencionais pelos quais essas formas são acionadas e os objetos são então originariamente vivenciados na prática segundo seu sentido ontológico ativado.

Vivencia-se uma experiência empírica endógena e prospectivamente preenchida pelos dados reais intencionalmente visados pelos jogadores no contexto da disputa, experiência que é assim gerada por formas sintéticas unificantes compartilhadas pelos jogadores. Dessa coerência entre sentido prático, atos perceptivos intencionais, açôes efetivas e ordem mais ou menos esperada das jogadas, tem-se consciência dos dados ao redor ${ }^{4}$ e precipita-se um impulso à ação contínua diante das disposiçóes excitadas nessa disputa real.

\section{Elementos físicos da experiência desafiadora de jogar}

\section{Objetos, ambiente, jogo e ação}

É condição fundamental e imprescindível ao jogo um cenário onde ele possa ocorrer, isto é, um espaço comum onde a ações possam se expressar 
de modo perceptível; onde possam efetivamente agir sobre ou sofrer a ação do outro, possibilitando a criaçáo um mundo prático circundante comum; onde possa, portanto, se constituir um complexo interativo sobre a base de uma zona intersubjetiva comum.

Em alguns jogos, o centro espacial dos eventos, onde os elementos relevantes se situam e se interconectam sob as formas de ação, é o tabuleiro, que atrai a atenção dos jogadores a um mesmo ponto à sua frente, fazendo com que todos se disponham ao seu redor. No jogo esportivo, esse ponto não pode ser apreendido tão facilmente em sua totalidade; ele sequer se situa fixamente. O campo de jogo é maior e cerca os jogadores, envolvendo seus corpos, demandando, como vimos, um esforço perceptivo de síntese constitutiva do que se passa

Nesse sentido, no espaço do jogo esportivo coletivo - incluindo o espaço entre os corpos ou em sua superfície - há objetos para a proteção; objetos que servem para um ajuste maior dos corpos ao ambiente e aos demais materiais do jogo (chuteiras, luvas); objetos que delimitam o campo, criando ponto de partida, demarcaçóes intermediárias e meta; objeto condicionante central às interaçóes, alvo das disputas, que é de controle mais ou menos incerto, sendo por isso capaz de convergir as atençóes - normalmente uma bola; e, em alguns esportes como o hóquei, materiais que servem para manipular o elemento central das interaçóes (taco, raquete etc.).

Como vimos, o objeto central da disputa, muito frequentemente uma bola, fica solto no ambiente, sujeito às forças físicas naturais que nele atuam, desempenhando a funçáo de núcleo gerador de toda a disputa e oferecendo um acento comum à realidade vivida pelos competidores. Suas propriedades físicas - seu peso e sua forma arredondada, por exemplo - devem permitir que ele seja movimentado pelos competidores com algum controle em meio a certo risco de descontrole. É o equilíbrio entre controle e descontrole que, no contexto do jogo, gera a constante concentraçáo e adesáo ao que está por vir. Por outro lado, em função da dependência em relação a esse objeto, a fluência interativa se deve à centralidade de seu papel e à sua propriedade de deslocamento contínuo no tempo e no espaço.
A essas forças naturais se acrescentam as forças humanas, individuais e coletivas, de meus oponentes, cujos objetivos e açóes são, nos termos do jogo, contrapostos aos meus; e de meus companheiros, por conta da interdependência entre nossas açóes, bem como pela própria dificuldade de nos coordenarmos na realização das açóes coletivas. É justamente em face desse conjunto de forças humanas (sociais) e naturais (ou físicas) que, bem articuladas, se determina como um jogador, parte integrante da equipe, deve se situar nesse desafio.

Todos esses elementos, portanto, em correlação ontológica, exercem funções constituintes de um ambiente comum, típico de um desafio esportivo, criando uma conexão total com o mundo, que entra em vigor por meio da ativação de uma competência prática competitiva já adquirida, capaz de gerar a predisposição a uma fusáo entre ambiente, objetos e corpos em uma só realidade intensamente vivida por todos, especialmente no fluxo da ação.

\section{O corpo, o jogo e a açāo}

Diante do jogo, o corpo, no qual a consciência se ressalta, é um dos elementos que, relacionados ao ambiente e aos objetos, fundem e sintetizam o ser e o mundo circundante sobre sua interface sensível a partir do engajamento obtido pela prática, ligando-os entre si e a si, enquanto o jogador situa os próprios movimentos no movimento dos demais.

Para compreender como isso acontece, o primeiro dado a se destacar é que, na experiência da prática esportiva, o corpo ganha relevo porque a atividade esportiva requer sua participação intensa. Sucedendo-se continuamente, os movimentos coletivos, sob sua lógica básica, seguem colocando desafios físicos concretos em interaçóes com os corpos dos demais jogadores e os objetos, exigindo que se realizem açóes que visam mantê-los competitivamente sob controle e engrenados na sequência interativa, razão pela qual são percorridos trajetos variados que exigem do corpo velocidade, resistência, elasticidade e força física incomuns na vida cotidiana - traço existencial que, em si, como parte de um modo de ser, distingue, no nível sensório-motor, a experiência do mundo do jogo esportivo da experiência ordinária. 
Nesse contexto, o corpo apresenta-se com um sentido de funcionalidade coletiva a que se liga não só a relevância ao exercício de sua capacidade fisiológica, mas também a sua aparência exterior, tal a importância teatral que seus movimentos adquirem diante do oponente e do próprio companheiro, tanto como ação de intervenção física direta sobre a ação destes, quanto como expectativa em relação à qual suas açóes se desdobrarão. Assim, como elemento de exibição de ação e ao mesmo tempo parte física dela, o corpo está presente no esforço de coordenação de cada um e de todos na constituição de ações coletivas eficientes nos termos do jogo. A dinâmica teatral é central. Porquanto o corpo, embora seja experimentado no exercício fisiológico intensificado, tem nessa dimensão incorporada um dado de fundo, já que a centralidade da disputa se refere ao modo como somos vistos, e como vemos os demais, plano dramatúrgico em que se mostra o que há de mais relevante nas interaçóes esportivas e em que se vive essa zona intersubjetiva dotada de luzes e sombras, de ocultaçóes e revelaçóes parciais, na sua plenitude de sentido.

Desse modo, torna-se imprescindível considerar que há, na consciência dos envolvidos, uma percepção aguda desse movimento corporal que coordena suas experiências. $\mathrm{O}$ que vivenciamos em um lance é um conjunto sintético de percepções diretas e de reflexos e deduçóes repentinas do movimento, ordenados de maneira mais ou menos convergente e em direção contínua, demarcada por pontos de inflexão mais ou menos abruptos que seguimos antecipando, capturando enquanto nos ajustamos. Imersos no enquadramento de uma situação determinada pela continuidade da ação coletiva, os jogadores estáo submetidos à dinâmica da disputa posturas corporais que se acomodam e criam um complexo formalmente organizado e reconhecível, em que cada jogador se vê refletido no olhar e no corpo do outro. A partir daí é que cada um se situa e segue agindo. Nesses termos,

Tudo se passa como se a intenção do outro habitasse meu corpo ou como se minhas intençôes habitassem o seu. $\mathrm{O}$ gesto que testemunho desenha em pontilhado um objeto intencional. Esse objeto torna-se atual e é plenamente com- preendido quando os poderes de meu corpo se ajustam a ele e o recobrem. O gesto está diante de mim como uma questáo, ele me indica pontos sensíveis do mundo, convida-me a encontrá-lo ali. A comunicação realiza-se quando minha conduta encontra neste caminho o seu próprio caminho. Há confirmação do outro por mim e de mim pelo outro (Merleau-Ponty, 1999, pp. 251-252). ${ }^{5}$

Esse "tudo que se passa...", em uma partida real, submete-se a uma lógica maior, a lógica prática totalizante do mundo do jogo. A localização dos dribles e movimentos corporais individuais assim como toda a resposta dos demais se referem ao contexto de uma estrutura sequencial da ação coletiva que se apresenta aos jogadores dotados de um mínimo de competência como síntese de movimentos individuais em movimentos mais ou menos totais e complementares.

Cada movimento e cada tomada perceptiva inserem-se no curso de ações coletivas que seguem sobre grandes eixos mais ou menos familiares. Ainda que circunstancialmente mal ajustados, permanecemos situados em campo com nossos corpos nessa ou naquela área, numa região mais iluminada ou de sobras, nessa ou naquela etapa da ação coletiva, sabendo que seguiremos por este ou por aquele caminho. É a partir desses conhecimentos compartilhados acerca do modo comum de jogar, que percebemos (ou acreditamos perceber) o que este ou aquele jogador faz no contexto do que estamos fazendo bem como igualmente (ao menos acreditamos) somos percebidos de vários ângulos pelos envolvidos a partir da forma de ação pertinente ao instante de nossa unidade interativa.

Desse modo, notamos que em nossos movimetos são reconhecidas, assim como reconhecemos nos movimentos do outro, intençóes mais ou menos complementares e totais que lhes conferem sentidos circunstanciais mais exatos. Todos respondem de modo lógico e correspondente a tais circunstâncias que todos acabam por produzir conjuntamente, desencadeando de parte a parte pontos de inflexão mais ou menos familiares na sequência de interações. 
E, assim, toda uma cadeia de gestos individuais ganha um sentido competitivo mais ou menos evidente, inter-relacionado, total, simultâneo e preciso. Trata-se de conjunto circunscrito e factual, identificado a formas típicas de ação que ligam de modo imediatamente inteligível os gestos dos companheiros contra os do oponente a partir do sentido prático que os anima: o de fazer a açáo coletiva de suas equipes prosseguir eficientemente na direção de seu objetivo, ocultando ao máximo sua intenção para surpreender o oponente.

\section{O corpo, a ação e as forças coletivas}

De acordo com a forma do jogo, a partida apresenta sempre um sentido imediato e contínuo de acirramento de disputas que se constituem no âmbito de um movimento coletivo aderente, que exige energia e coordenação dos jogadores na sustentação da realizaçấo da ação coletiva de sua equipe contra a resistência da equipe adversária.

Em razáo disso, e diante da interdependência entre os núcleos em que essas disputas se colocam, revela-se um sentido coletivo, que os integra e os identifica como o que nós estamos fazendo em confronto com o que eles estâo fazendo; sentido que atravessa toda a cadeia interativa sob um mesmo referencial de organizaçáo e um mesmo espírito de conjunto. Isso apontaria para a existência de um ser coletivo em ação, que nos englobaria e que seria supostamente a fonte geradora dessa ação e de sua energia, cuja força ou fraqueza se manifestaria circunstancialmente durante a partida.

Assim, todos estariam impregnados desse sentido e dessa suposta força todo que nós juntos conformamos. A açáo coletiva no contexto do jogo, diante da força e da resistência do adversário, seria justamente o meio de expressão desse suposto ser coletivo. Ao jogar, todos se predispóem a que essas forças mutuamente contrapostas surjam entre nós e impregnem a realidade experimentada em comum a partir dos eventos do jogo.

Nas disputas, das vivas impressóes que se sucedem e se sintetizam no tempo, esse sentido competitivo é continuamente acirrado, ressaltando seu aspecto de agonia de tensão entre as duas partes em disputa que inspira e impulsiona as açôes ain- da mais adiante, manifestando-se nessa excitação crescente sobre o ambiente. O que indica como um conjunto de forças vivenciadas como transcendentais ${ }^{6}$ incide sobre o ser, produzindo justamente a adesão dos jogadores entre si, a seus corpos e ao ambiente como partes de uma coletividade, com um só sentido prático total.

\section{A ordem do jogo}

\section{A ordem das interaçôes}

Vimos que todos os eventos de uma partida nascem de um núcleo dinâmico gerador de uma disputa; um núcleo cuja lógica é capaz de produzir interaçóes que envolvem todos os participantes, em um modo prático bastante ligado à dimensáo corporal e espacial da vida, conformando, prospectivamente, um espaço comum de experiência, uma disputa no âmbito de uma unidade interativa real.

Como dissemos acima, há um núcleo central da disputa ligado a outros que gravitam ao seu redor, integrando, tal a sua interdependência, os diversos jogadores em um só complexo interativo. Esses núcleos, apesar de serem abertos, interdependentes e convergentes, podem assumir uma dinâmica interna e demarcaçóes temporais próprias no curso da mesma unidade interativa. Assim, por exemplo, em uma partida de basquete, enquanto num lado da quadra o armador e o pivô da equipe no ataque realizam um pick and roll contra a dupla de defensores que os marcam individualmente (núcleo de disputa C), no outro lado da quadra de ataque, simultaneamente, um pivô do time atacante bloqueia a passagem do marcador de um ala de sua equipe (núcleo de disputa $\mathrm{D}$ ), que então se desloca para receber mais facilmente do armador envolvido no pick and roll um passe e arremessar desmarcado diante do atraso do defensor que fora bloqueado. Trata-se de duas disputas paralelas que se encontrarão adiante para a conclusão de uma só jogada adiante no tempo. Desse modo, a partir de certo momento, o pick and roll e o bloqueio (núcleos distintos, $\mathrm{C} \mathrm{e} \mathrm{D)}$ poderâo desembocar em outra configuraçáo maior com a opçáo que o ala livre entáo apresenta ao armador, dissolvendo-se ambos os núcleos anteriores 
em uma jogada mais abrangente com um núcleo concernente a toda a jogada, com o arremesso à cesta. $\mathrm{O}$ quadro referencial das açóes segue mudando até a conclusão da unidade interativa.

Como esse complexo interativo se conforma e se modifica? O que se passa em cada núcleo de disputa configura um conjunto sintético de eventos simultâneos, sucessivos, interdependentes e logicamente encadeados, de modo direto ou mediado, mas sempre integrados pelo vínculo com o núcleo gerador central, que gira em torno da bola, predispondo-se a se configurar e reconfigurar no aqui e no agora em face do modo como os jogadores agem uns em relação aos outros. Pela condicionalidade em relação a esse núcleo, descreve-se uma só linha progressiva de eventos, cujo sentido se orienta ao objetivo coletivo maior, que ajuda a sintetizar o que se passa a cada instante em todo o campo no transcorrer da unidade interativa. Ora esses núcleos se encontram formando um só conjunto interativo com organização única, ora se separam e se individualizam, deslocando-se, mas guardando sempre o sentido coletivo a ser alcançado. Na progressão da ação coletiva há, portanto, momentos de divergência - pluralização coordenada dos núcleos de disputa, geralmente no meio da unidade interativa - e de convergência - até a concentração e a unificação dos núcleos.

São a forma da disputa e o efetivo exercício da força ofensiva e defensiva, sob a gramática familiar do jogo, que, em última instância, dão fluidez e enredam a ação em um sentido prático arrebatador. Todos agem simultânea e sucessivamente sob a organização dessas formas referenciais, o que possibilita a coordenação das açóes em cada núcleo de disputa. Mas como entender o fundamento da ordem interativa? Os jogadores certamente lançam mão de recursos dramatúrgicos, no sentido em que Goffman utiliza o termo, isto é, o de que entra em curso um esforço de manipulação coletiva das impressóes por parte de uma equipe que busca fabricar uma realidade, "induzindo a oponente a ter uma falsa opinião sobre o que está se passando. Um plano perverso está envolvido, uma trama ou um plano traiçoeiro conduzindo - quando realizado - à falsificação de alguma parte do mundo" (Goffman, 1975, p. 83).

Os atacantes, diante do esforço defensivo dos oponentes, buscam criar espaços com dribles e pas- ses a fim de encontrar um trajeto do ponto de partida à meta. Para criar tais espaços na defesa por onde seguir avançando com a bola, os atacantes, individualmente ou em conjunto, devem simular movimento a fim de gerar desajustes momentâneos na defesa, criando zonas problemáticas que atraiam a atenção para um conjunto de possibilidades de continuidade da ação a ser marcada para que, então, desta possam emendar repentinamente uma ação em outro sentido e de modo surpreendente, dificultando a ação defensiva.

Os atacantes se veem diante dessa maneira de proceder porque os defensores se empenham em realizar açóes de pronto ajuste e fechamento desses espaços em direção à meta, visando defendê-la, açóes que também podem ser de indução do atacante às piores escolhas e ao erro ou mesmo de ruptura da ação ofensiva. Nesse intento, os defensores buscam intensificar a impressão de que todos ou alguns espaços por onde a bola possa ser conduzida estão ou estarão fechados, utilizando para isso posiçóes coletivamente organizadas em campo, bem como gestos corporais que ampliem os espaços ocupados numa configuração tática específica. Com isso, as açóes de defesa visam inibir açóes ofensivas potencialmente mais eficientes, orientando as escolhas dos atacantes a direçóes menos favoráveis, afrouxando ou intensificando a marcação em pontos estratégicos do curso da ação ofensiva, modelando assim o avanço da cadeia interativa a seu favor.

Desse modo, atacantes e defensores, na simultaneidade e na sucessão, estão continuamente interligados no fluxo imanente da mesma experiência na medida em que suas açóes se referenciam e complementam, constituindo e atualizando nessa zona intersubjetiva a problemática situacional que se coloca entre nós.

Forças de concentração e de descentramento nos esportes coletivos

Dependendo da forma da disputa, a sucessão de eventos nas unidades interativas pode ser mais concentrada em uma só linha progressiva bem determinada, capaz de envolver todos os jogadores em um só núcleo de disputa, que adquire, então, características totais e abrangentes, não permitindo um 
grande distanciamento espacial ou temporal entre potenciais núcleos. Com efeito, esta linha única é apreensível de imediato em sua quase totalidade por cada jogador - como ocorre no voleibol. Nesse esporte, todos os jogadores se veem envolvidos continuamente num mesmo núcleo coletivo mais íntegro de disputa, que envolve todos os atacantes e defensores praticamente ao longo de toda a sequência das unidades interativa, do saque até o momento em que a bola cai no chão.

Em outros tipos de competição, a sucessão de eventos, apesar de se desenvolver também com base em um eixo coletivo principal - como é típico dos esportes aqui tratados -, acontece de maneira diferente. Núcleos periféricos mais restritos de disputa se conformam orbitando o eixo central em torno da condução da bola. Despontam, portanto, outras linhas de disputa que ora se cruzam, ora se unificam, ora se separam desse eixo, preservando-se os elos de interdependência, funcionalidade e solidariedade na constituição prospectiva e imanente das açóes coletivas de ataque e defesa. Desse modo, embora inter-relacionados em um mesmo complexo interativo, nesses esportes, tais núcleos podem evoluir mais descentrados no tempo ou no espaço, deslizando sobre o conjunto dos jogadores e por todo o campo de jogo, transformando suas funções e o todo interativo em que se inserem, assumindo, cada um, no fluxo de cada jogada, posiçōes ora mais centrais ora mais periféricas.

Vejamos como se observa tal descentramento relativo da experiência em núcleos distintos de disputa no futebol de campo e no futebol americano, tendo como termo de comparaçáo o maior grau de concentração ou de centramento das ações no voleibol.

No futebol de campo, temos uma série de características da forma da competiçáo que implica a tendência a um descentramento predominantemente temporal dos núcleos de disputa. Muitos jogadores e um espaço de amplas dimensóes entre o ponto inicial e a meta, sem maiores limites temporais à ação coletiva, fazem com que esta tenda a se prolongar, embora se torne mais suscetível à interrupção pelo fato de a bola ser conduzida com os pés, o que é um dado relevante para a divisão de funçôes mais defensivas ou ofensivas entre seus jogadores, já que se pode perder a bola a qualquer momento. A prática passa então a se caracterizar por uma cadeia de açóes relativamente longa, porém instável, na constituiçâo de uma ação coletiva eficiente e na tendência a um distanciamento temporal e espacial maior entre os núcleos de disputa em relação ao voleibol.

Em conjunto, esses fatores, ao menos potencialmente, resultam numa maior distância temporal entre a participação mais ativa de um grupo de jogadores, cuja função se concentra numa etapa da unidade interativa, que a de outros, voltados à outra etapa da açáo coletiva mais adiante, assumindo circunstancialmente uma posição mais periférica como demonstra, por exemplo, a distância entre, de um lado, o envolvimento do goleiro e dos zagueiros e, de outro, o dos atacantes, nas cadeias típicas de ação coletiva, distância preenchida por um setor intermediário, o de meio de campo. Só em alguns raros momentos todos participam ativamente num mesmo lance. A cada momento, uns se veem envolvidos nas disputas mais centrais em torno da bola, enquanto outros se encontram mais distantes. Por essa razão, para que uma ação coletiva seja bem coordenada, há, nesse esporte, a necessidade de ordenação de caráter mais acentuadamente temporal entre o que se passa nos núcleos mais ativos e periféricos de disputa, que é o que justamente possibilitaria o encadeamento prático das ações individuais ao longo do tempo como parte de uma só ação coletiva.

Embora a dimensão espacial dessa unificação o posicionamento entre os jogadores no campo também seja importante, o ajuste prático requerido pelo futebol deve ser feito em continuidade e em ritmos adequados para que a ação se mantenha com possibilidade de ser eficiente. Porquanto surge a preocupaçáo com o tempo de cada ação individual em relação ao da outra que, por sua vez, determina a importância da ocupação adequada do espaço ao redor para que se dê a coordenação e o ajustamento mútuo na evolução da açẫo coletiva, incluindo-se aqui a transição entre ataque e defesa, já que a posse da bola é bastante precária devido à conduçấo com os pés. Enfim, o tempo da ação é central à coordenaçãoo entre as açóes individuais, especialmente porque o espaço a ser percorrido para um ajuste rápido é amplo demais, porque não há limites temporais e porque os movimentos entre 
uma parte da equipe e outra envolvem a possibilidade de se distanciar demais no tempo, inviabilizando sua continuidade.

Já no futebol americano, há uma tendência a um descentramento predominantemente espacial. Nesse esporte, as açóes coletivas são relativamente mais curtas. Devido à regra segundo a qual a cada 10 jardas alcançadas tem-se mais 3 chances para alcançar mais 10 jardas, até se chegar à meta, e devido ao equilíbrio entre atacantes e defensores, as unidades interativas são picotadas no tempo. Cada parte dessa unidade interativa, em geral, conclui-se bem mais rapidamente do que no futebol. O tempo das ações coletivas é significativamente menor para que ajustes mútuos ocorram ao longo da ação coletiva. Por isso, os núcleos de disputa diversificam-se, assumindo funçóes e posiçôes diferentes, desdobrando-se de modo bastante concentrando, localizados em áreas específicas, devendo encaixar-se o mais precisamente possível no breve tempo da ação coletiva. Não há muito tempo para reorientação das ações individuais. Assim, o tempo para sínteses perceptivas a serem realizada pelos jogadores entre o que se passa aqui e lá, a fim de se coordenar com as demais ações, não comporta grande amplitude; acentuam-se aspectos mais marcadamente espaciais concernentes ao núcleo que ocupam.

Os jogadores distribuem-se em núcleos funcionalmente mais espacializados e bastante absorventes de disputa, espalhados no campo em uma ação rápida para que sínteses temporais tenham a mesma importância que no futebol. Poucos são os passes e a velocidade das açóes é maior e, a partir de um determinado momento, constantemente progressiva até a sua conclusão. Após determinado ponto da ação coletiva (a disputa logo após o snap), os ritmos geralmente se modificam pouco. Como padrão, a unificação necessária à continuidade da ação refere-se, em comparação com o futebol e o voleibol, mais ao que ocorre no espaço da ação coletiva e menos no tempo. Assim, nesse esporte, as ações, do ponto de vista dos jogadores, partindo do ponto do espaço onde se localizam, do núcleo onde se situam, devem se integrar em açóes bem planejadas, prosseguindo de modo coordenado e o menos problemático possível em relação aos mais próximos na sequência da cadeia de ação coletiva.
Nesse jogo, todo o sentido fundamental da cadeia interativa depende do que o quarterback faz. $\mathrm{O}$ passe que inicia a disputa, a ele endereçado, estabelece a conexáo entre os jogadores. Cada um age nessa disputa absorvente que me concentra no aqui, no agora e no oponente ao meu redor, dando como certo (taking for granted) certa expectativa mais ou menos comum de orientação de ação do quarterba$c k$, dos outros jogadores e de toda a interação, que é factualmente atualizada durante o seu desdobramento. Já em seu início, embora $e u$ ainda não saiba muito sobre a continuidade real da interação, sei da organização típica total da ação de minha equipe e que a ação real dependerá do que todos e cada um, atuando em outros núcleos de disputa, deverão fazer. Mas nesse esporte não tenho tanto ângulo perceptivo e tempo para produzir essa integração no tempo, como há em outros esportes.

Como se pode notar, o modo pelo qual cada prática determina como os jogadores se inserem na ação coletiva e como devem fazer para que ela seja efetiva indicam o tipo de experiência que cada esporte proporciona. Uma distinção conceitual pode nos ser útil aqui para compreender as diferenças na ação do ponto de vista da coordenação. Segundo Schutz (1967a, p. 68), Husserl diferencia os atos de consciência que produzem sínteses contínuas, monotéticas, dos que realizam sínteses descontínuas, politéticas. Um ato perceptivo - um tipo de ato de consciência - poderia ser, ao mesmo tempo, sintético e politético.

Para compreendê-lo, temos que ter em mente que, em sequência, os atos perceptivos repercutem uns nos outros de maneira regular, conformando um ato intencional de consciência total. Assim, em função de uma intencionalidade, no nosso caso, da prática e de todo um sentido existencial, esse ato se volta, ordenadamente, à constituição de um objeto total, dotado de um noema referencial. Haveria mesmo, segundo Gurwitsch (1957), uma correspondência transcendental entre o sentido do ato de consciência e o objeto típico visado, gerando a síntese perceptiva resultante de um só processo perceptivo apoiado em uma espécie de superposição entre ato do sujeito consciente e objeto visado.

É preciso considerar que cada ato busca um aspecto da aparência desse objeto temporal, real e 
familiar - a jogada em curso - pela obtenção de dados reais, por um ou outro relance imediato (monotético) de atenção sobre essa jogada. Jogada que entấo, em cada instante, como parte de uma totalidade contextual mais ou menos familiar, sugere ao jogador como prosseguir, tal sua estrutura noemática conhecida, sustentando a adequação da própria ação à situação. $\mathrm{O}$ ato sintético resulta justamente desses vários raios de atençấo sucessivos e, em alguns casos, descontínuos no tempo, que são prospectiva e logicamente integrados pela consciência sob a ordem familiar da atividade, induzindo a que as várias tomadas potencialmente parciais de consciência da aparência dessa jogada se insiram e se organizem como parte de apenas uma jogada. Esse ato é, portanto, ao mesmo tempo, sintético (ou monotético) e politético: "politético porque dentro [dessa unidade] várias teses diferentes estão colocadas. É sintético porque elas são colocadas juntas" (Schutz, 1967a, p. 68).

Podemos então considerar que, enquanto jogamos, cada ato perceptivo de cada jogador é integrante de um ato intencional total que se orienta a partir do objeto visado, uma jogada (do ponto de vista de quem joga, um objeto circundante, com propriedades corporais, espaciais e temporais), e por um mesmo sentido prático; sentido esse que se orienta por expectativas perceptivas geradas por experiências vividas, que guiam o sentido da experiência atual segundo as mesmas práticas compartilhadas do jogo e do modo como o conjunto dos jogadores em interação, intencionalmente ou não, individual ou coletivamente, as evocam com suas açôes.

Dadas as formas lógicas, fornecidas pelo jogo, em que podem fazê-lo, a distinção na constituição da experiência dos esportes aqui em questão se coloca nos seguintes termos: no voleibol há poucas rupturas que desviam o ângulo perceptivo dos jogadores do núcleo central da disputa - há aqui a tendência a uma sucessão ininterrupta de sínteses monotéticas sucessivas voltadas para o mesmo ponto à frente, criando a unidade das jogadas; já no futebol e no futebol americano, os núcleos de disputa emergem e se movimentam, demandando deslocamentos perceptivos de maior amplitude no tempo ou no espaço, alterando mais frequentemente os ângulos para tomadas perceptivas. Todo o campo perceptivo lança-se a pontos distintos do campo de acordo com a dinâmica de descentramento espacial ou temporal dos núcleos, exigindo dos jogadores uma alternância rápida de eixos e um esforço de síntese politética a fim de preservar a continuidade de uma só linha referencial à qual suas açôes deverão se ajustar.

Desse modo, enquanto se movem, esses atos perceptivos devem fazer com que os núcleos se revezem no primeiro e no segundo plano (como figura ou como fundo) de acordo com o acento dado ao conjunto interativo, seja na função ofensiva de sustentar a condução da bola, seja na função defensiva de fazer frente ao atacante, antecipando-se e ajustando-se ao seu movimento, impedindo seu avanço. Tudo isso articulado às açôes dos companheiros e adversários, tendo como base o referencial de uma consciência incorporada e formas de ação compartilhadas entre os praticantes do esporte.

Portanto, nos esportes coletivos, dentro dos limites transcendentais de sua forma constitutiva de disputa, o avanço ou recuo da bola e de todo o complexo interativo ganha um significado bem contextualizado e preciso sobre o eixo direcional que se estabelece entre as metas, pois transcorre como resultado de disputas microscópicas entre atacantes e defensores nos diversos núcleos que atuam em uma partida. A forma do jogo predetermina a lógica e os limites constitutivos da interaçâo total, com características que, como vimos, variam dependendo de que esporte se trata - predominando ora a concentraçáo em um mesmo núcleo, ora o descentramento entre os vários núcleos; com caráter ora mais espacial, ora mais temporal. A forma do jogo impóe, assim, limites ao esforço do jogador na constituição das ações coletivas e singulariza a experiência de jogar este ou aquele esporte.

\section{A ordem das relaçōes}

Para compreender o jogo em sua totalidade e capacidade de ocasionar uma relaçáo competitiva envolvente do início ao fim de uma partida, devemos entendê-lo como uma ordem de atividade que abarca, além da dimensão mais imediata das interaçôes, outra, voltada a uma dimensão temporal mais alargada, que se refere justamente à definição de po- 
sições entre os competidores, isto é, à determinação de quem está na frente ou atrás no placar, e sempre a partir do que se faça em campo ao longo das interaçóes. $\mathrm{O}$ modo como o jogo organiza o encontro nessa dimensão chamo de "ordem das relaçôes".

A realidade nesse tempo mais alargado do jogo resulta do modo como a sucessão dos eventos segue se produzindo, se acumulando, se sintetizando e se acomodando, para depois, diante de novos eventos, se reconfigurar. Isso gera a percepção imediata, relativa e continuamente atualizada das duas forças em confronto. Trata-se do resultado da tensão entre as impressóes deixadas pelo acirramento das disputas no transcorrer do tempo, impressóes que, em síntese, impregnam o ambiente e cujo embate evidencia um sentido de igualdade ou superioridade de uma em face da outra.

A síntese dos eventos em sucessão constitui o tempo vivido da partida, ressaltando-se justamente as supostas potencialidades essenciais vivas e manifestas nos feitos das equipes e dos jogadores. Tais feitos - muitos deles traduzidos em números sob certas categorias consideradas relevantes pelas regras no sentido de apurar o melhor, como o placar, embora nem todos cheguem a assumir essa forma -, gerando de imediato a intuição das forças relativas demonstradas ao longo do tempo, tornam-se capazes de revelar aquelas potencialidades supostamente essenciais. Essas forças - a substância sensível dessa experiência - resultam dos lances que seguem se produzindo na zona intersubjetiva temporal de nossa disputa, a qual podemos entender, desse modo, como um espaço de posiçóes que envolve e organiza o que se passa entre nós e ao nosso redor. Assim, desde o início da partida, os lances seguem se sintetizando no agora, ressaltando-se na sucessão, uns sobre outros, atualizando em continuidade um horizonte estruturado pela ordem da relação, do início ao fim.

Sob tal ordem, nossas forças coletivas - de minha equipe e da adversária - emergem, uma diante da outra, em uma tensão constitutiva da substância dessa realidade que nos anima. Apercebo-me como parte de uma dessas forças, sem, entretanto, deixar de ter um senso profundo de minha individualidade, já que é concentrado em mim, ao mesmo tempo como parte do todo - como agente cujo ponto de partida existencial já me inseriu nesse ser coletivo de minha equipe (tendo assumido seus desafios, sua posição etc.) e cuja ação já se situa entre ações que igualmente confluem com as demais no sentido de realizar a ação coletiva - que posso efetivamente jogar. Nessa prática, portanto, enquanto me individualizo em uma concentração profunda na ação, me conecto e identifico, no interior desse fluxo concentrado, aos demais e no todo de uma equipe a cujas ações e vontade me encontro fortemente ligado, em última instância, por uma determinação formal da prática e pelo sentido de um desafio que é, além de individual, coletivo. Enfim, há uma disposição prática existencial, pré-pessoal, determinada pelo jogo, que impulsiona a ação adiante em uma experiência integrada e envolvente.

As regras oferecem as condições para que as expectativas de sucesso do melhor time em campo, próprias de jogos agonísticos, se confirmem e, ao menos em sua maioria (vale lembrar que esse é um quesito problemático especialmente para o futebol), se realizem. Por isso, é necessário um sistema de pontuação e registro de violaçóes que permitirá a conformação de uma ordem competitiva endógena à partida, com o intuito de se obter um resultado justo. Esse sistema serve ao propósito de unir o alcance da meta à construção do resultado. A coerência, a inteligibilidade e a totalidade desse sistema garantem um desafio excitante e recompensador.

Ambas as dimensões - interativa/relacional, espacial/temporal - geralmente são articuladas por mecanismos de definição, acumulação e objetivação numérica oficial dos eventos. Trata-se de dispositivos previamente estabelecidos de acordo com um princípio integrador de justiça, baseado em critérios de excelência e competitividade. São eles que, seja na ação ou no pensamento de senso comum dos jogadores, seja na aplicação oficial da regra, mantêm os eventos integrados e atualizados; daí o sentimento de unidade e completude próprio de uma experiência singular.

De acordo com essa inter-relação entre ordem interativa e ordem da relação que se pretende (ou que se dá como certo ser) justa, define-se uma expectativa agonística baseada em uma organizaçáo fundamental. Pois o jogo se apoia na ideia de que alcançar a meta (que ele mesmo define) manifes- 
ta competências e habilidades interativas (o que se dá no plano da ordem das interaçóes) que se póem à prova; mas de modo que, num plano temporal mais estendido, o sistema de pontuação e de registro de outros quesitos possibilite, em suas objetivaçóes e decorrências, apurar de modo justo a definição do melhor ao longo de uma partida. Isso traz outra competência, que não a de saber pontuar e defender, mas que se refere à disputa coletiva nesse tempo maior da partida, ou seja, a competência de se manter na frente do placar ou de sair de uma posição inferior, ao longo da sucessão das interações, por meio de uma inserção interativa e de açóes coletivas logicamente de acordo com a posiçáo que se ocupa em relação à que se deseja ocupar - isto é, por meio de uma tática adequada inserida em uma estratégia pertinente e eficaz.

Diante dessa interconexão, os jogadores prosseguem sob o efeito aderente, sob a força centrípeta do jogo, que atua sobre si no sentido de integrar eu e eu mesmo, meu corpo, os dos demais, os objetos e o espaço, eu e minha equipe, nosso time e (versus) o deles, em uma experiência envolvente, íntegra e contínua no espaço e no tempo vivo e factual de nossa partida - uma experiência que se distingue pela vivência do fluxo.

\section{Conclusáo}

O jogo condensa e precipita a vida nos seus limites espaço-temporais, em uma relação sintética e intensificada com o mundo em questão. Ele acentua o caráter de desafio presente na existência humana ao estabelecer previamente correspondências entre competências, fins e meios, encerrando as polarizações na relação do jogador com o universo desafiante estabelecido circunstancialmente na partida, aderindo e conduzindo a experiência de todos na atividade.

Nessa perspectiva, pode-se entender como o jogo atua sobre o modo de ser dos indivíduos. Como afirma Gadamer (1997), o jogo joga enquanto é jogado, no sentido de que os jogadores se veem nesse ir e vir das interaçóes, em um permanente, ordenado, circular e progressivo ser e deixar fazer, como diria Heidegger (2005, pp. 129-130), ou em um fazer e padecer, de acordo com Dewey (1958, pp. 13-19, 41), ou ainda, como diria Wittgenstein, num guiar e ser guiado por regras (1996, p. 83).

Durante a partida, os jogadores, enquanto se assenhoram de si, lançam-se e permanecem conscientes das situaçóes ali apresentadas, as quais, como vimos, têm uma estrutura adequada ao arrebatamento coletivo: equilíbrio entre movimento e náo movimento, entre controle e descontrole, entre força e resistência - aspectos determinados pela ordem prática transcendental do jogo. Por um lado, dá-se ao jogador certo controle sobre os eventos; por outro, sincrônica ou diacronicamente, o adversário assume o domínio - tudo em proporção adequada, respeitando certa noção de igualdade formal, de tal modo que, ao se demonstrar que a capacidade redundará em vantagem (e não o acaso), se preserve o sentido de desafio e o engajamento na disputa em face da confiança na justiça agonística do jogo.

Em resumo, esse equilíbrio deve ser traduzido na forma concreta da disputa, gerada pelo conjunto de regras com o propósito de sustentar o interesse, gerar mobilização interior, enfim, a manutenção do sentido de desafio da disputa. Esses elementos lógicos transcendentais convertidos no conjunto de regras são fundamentais para produzir envolvimento e, portanto, para estabelecermos os nexos que nessa atividade ligam o ser ao mundo, conferindo ao jogo o sentido de totalidade desafiadora que caracteriza e estimula a experiência de jogar e seu caráter de autenticidade, como a entende Heidegger (2005, pp. 256-257).

Em função das regras constitutivas, como diria Searle (1995, p. 27), o jogo, em sua ontologia, como argumentamos aqui, transforma-se em um mundo a que corresponde toda uma ordem esportiva de existência. Um mundo em relação ao qual o ser se alinha junto com outros para competir contra o oponente sob a forma lógica básica desse jogo, de acordo com a qual uma dinâmica competitiva real se desdobra fluentemente em uma mesma corrente arrebatadora de eventos a que a experiência de agir se ajusta. Forma que se apresenta como ordem de uma mesma realidade inteligível, coerente, contínua, presente tanto na dimensão espacial e corporal da experiência, envolvendo objetos físicos, quanto 
na dimensão temporal, em que se situa um espaço relacional no qual segue se definindo quem está melhor ou pior e, ao final, o vencedor e o perdedor da partida. Tudo integrado em uma experiência única e plena, revelando, ao menos supostamente, as reais potencialidades do ser mais próprio e autêntico na ação viva e real.

\section{Notas}

1 Para as contribuiçóes dos autores citados ao entendimento do fenômeno do jogo, ver especialmente Garfinkel (1963) e Goffman (1961).

2 Vale aqui a referência ao clássico trabalho de Huizinga sobre o jogo: "Numa tentativa de resumir as características formais do jogo, poderíamos considerá-lo uma atividade livre, consciente, tomada como 'não séria' e exterior à vida habitual, mas ao mesmo tempo capaz de absorver o jogador de maneira intensa e total. É uma atividade desligada de todo e qualquer interesse material, com o qual náo se pode obter qualquer lucro, praticada dentro de limites espaciais e temporais próprios, segundo certa ordem e certas regras" (2005, p. 16).

3 Vale como ilustraçáo a referência ao depoimento de Oscar (um dos maiores jogadores da história do basquetebol no Brasil) em relação à experiência que o jogo de basquete pôde lhe propiciar: "Todos devem lembrar-se de quando, certa vez, Airton Senna disse que conversou com Deus. Posso dizer que entendo o que ele sentiu. Tudo acontece em um momento de tamanha intensidade, de tamanha agonia, que até parece que o mundo está em câmera lenta. Parece que sabemos o que vai acontecer. Sabemos que não vamos errar. Parece que temos o controle sobre o jogo e sobre as pessoas. $\mathrm{Na}$ verdade, não sei exatamente como definir esse momento; passei por essa situaçáo mil vezes, e é uma forte sensação de poder, de confiança, de controle, com o que não há nada parecido. Você é o 'senhor do jogo'. Era como me sentia: senhor do jogo. Nada sairia errado, nada sairia do controle, como é bom sentir isso! Entretanto, isso não acontece de acordo com sua vontade, você tem que estar extremamente bem treinado, física e tecnicamente, e tem que estar num estágio de concentração e intensidade fora do normal" (ver Schmidt, 2009, p. 66).

4 Sobre a interessante tese da emergência endógena da percepção e sua relação com as formas, ver Gurwitsch (1957).
5 Sobre a aplicação dessa ideia na interpretação do drible, ver Nazareth (2012).

6 Na perspectiva de Garfinkel, aqui adotada, a ideia de transcendentalidade ou de imortalidade é entendida como a síntese de experiências convertidas em uma ordem de atividade, que se apresenta sobre as existências individuais diante do cenário da prática em questão, no nosso caso o cenário do jogo. Ambas as expressóes são usadas pelo autor: "para falar de ocupaçôes humanas com base nas quais os membros locais, estando em meio à organizaçáo das coisas [organizational things], sabem, a partir dessas coisas em meio às quais estáo, que elas os precedem e que estarão lá depois que partirem. Imortal é uma metáfora para a recorrência da sociedade ordinária, [...] produzida, observada, observável, local e naturalmente descrita [accoutable] em e a partir de uma 'reuniáo de hecceidades”' (Garfinkel, 2002, p. 92).

\section{BIBLIOGRAFIA}

BOURDIEU, Pierre. (1983), "Como é possível ser esportivo?", in __ Questóes de sociologia, Rio de Janeiro, Marco Zero, pp. 136-163. . (1987a), "Epace social e pouvoir symbolique", in ___ Choses dites, Paris, Minuit, pp. 147-166.

. (1987b), "Pour une sociologie du sport”. in _ Choses dites, Paris, Minuit, pp. 203-216.

. (1990), The logics of practice. Stanford, Stanford University Press.

CICOUREL, Aron. (1974), Cognitive sociology, language and meaning in social interaction. Nova York, Free Press.

CSIKSZENTMIHALYI, Mihalyi. (2008), Flow: the psychology of optimal experience. Nova York, Harper Perennial.

DEWEY, John. (1958), Art as experience. Nova York, Capricorn Books.

(1974), Jonh Dewey: textos selecionados. São Paulo, Abril (col. Os Pensadores).

ELIAS, Norbert \& DUNNING, Eric. (1992), A busca da excitação. Lisboa, Difel.

GADAMER, Hans-Georg. (1997), Verdade e método. Petrópolis/Bragança Paulista, Vozes/Editora Universitária São Francisco. 
GARFINKEL, Harold. (1963), "A Conception of, and experience with, 'trust' as a condition of stable concerted actions", in O. J. Harvey (org.), Motivation and social interaction: cognitive determinants, Nova York, The Ronald Press Company. . (2002), Ethnomethology's program: working out Durkheim's aphorism. Boston, Rowman \& Littlefield.

GOFFMAN, Erving. (1961), Encounters: two studies in the sociology of interaction. Indianapolis/ Nova York, The Bobbs-Merrill. . (1975), A representação do eu na vida cotidiana. Petrópolis, Vozes.

GURWITSCH, Aron. (1957), Théorie du champ de la conscience. Bruges, Desclé de Brouwer.

HEIDEGGER, Martin. (2005), Ser e tempo. Petrópolis, Vozes, parte 1.

HUIZINGA, Johan. (2005), Homo ludens. São Paulo, Perspectiva.

HUSSERL, Edmund. (1959), Fenomenología de la consciencia del tiempo inmanente. Buenos Aires, Nova.

JACKSON, Susan A. \& CSIKSZENTMIHALYI, Mihalyi. (1999), Flow in sports. Estados Unidos, Human Kinetics.

MEAD, George Herbert. (1934), Mind, self, and society: from the stand point of a social behaviorist. Chicago, University of Chicago Press. . (2002), The philosophy of the present. Amherst, Prometheus Book, 2002.

MERLEAU-PONTY, Maurice. (1999), Fenomenologia da percepção. São Paulo, Martins Fontes.

NAZARETH, Eduardo Fernandes. (2012), "Drible, uma experiência fenomenal”. Cadernos do Sociofilo. Disponível em http://sociofilo.iesp. uerj.br/wp-content/uploads/2012/05/2_Eduardo.pdf.

. (2013), Esporte como experiência: uma análise fenomenológico-pragmática da constituição do jogo coletivo. Rio de Janeiro, tese de doutorado, Instituto de Estudos Sociais e Políticos, Universidade do Estado do Rio de Janeiro.

SCHMIDT, Oscar. (2009), Oscar Schmidt - conquistando o sucesso: a trajetória de Oscar Schmidt no basquete e na vida. Campinas, Komedi.

SCHUTZ, Alfred. (1964), "Making music together: a study in social relationship", in Arvid
Brodersen (ed.), Alfred Schutz. Collected papers II: studies in social theory), The Hague, Marinus Nijhoff, pp. 159-178. (1967a), The phenomenology of the social world. Evanston, Northwestern University Press.

. (1967b), "Common-sense and scientific interpretation of human action", in Maurice Natason (ed.), Alfred Schutz. Collected Papers I: The problem of social reality. The Hague: Martinus Nijhoff, pp. 3-47. . (1979), Fenomenologia e relaçóes sociais. Rio de Janeiro, Zahar.

SEARLE, John. (1995), The construction of social reality. Nova York, The Free Press.

WACQUANT, Loïc. (2002), Corpo e alma: notas etnográficas de um aprendiz de Box. Rio de Janeiro, Relume Dumará.

WITTGENSTEIN, Ludwig. (1996), Investigaçóes filosóficas. São Paulo, Nova Cultural. 


\section{AÇÃO E EXPERIÊNCIA NOS ESPORTES COLETIVOS}

\section{Eduardo Fernandes Nazareth}

Palavras-chave: Fenomenologia; Jogo; Esporte; Experiência; Prática.

O objetivo deste trabalho é compreender a constituição da experiência em jogos esportivos coletivos, como futebol, basquetebol, voleibol, handebol, entre outros. Tal experiência é determinada pelo curso da ação coletiva requerida e permitida pela forma do desafio gerado. Características como a criação de metas a serem alcançadas contra outra equipe, sob a lógica de uma mesma ação coletiva submetida à lógica do jogo, conduzem e ordenam todo o curso da experiência dos jogadores, ocasionando uma vivência coletiva singular, comumente retratada por praticantes como excitante e arrebatadora. O que caracteriza essa experiência? Como esses jogos as propiciam? Qual sua estrutura fundamental? Essas são as questôes fundamentais deste artigo.

\section{ACTION AND EXPERIENCE IN COLLECTIVE SPORTS}

\section{Eduardo Fernandes Nazareth}

Keywords: Phenomenology; Game; Sport; Experience; Practice

The purpose of this article is to understand the constitution of the collective experience of playing sport games as football, basketball, volleyball, handball, among others. Such experience is understood as determined by the course of the collective action required and permitted by the form of the challenge created by those games. Characteristics such as the creation of goals to be achieved against another team, under the logic of one and same collective action subjected to the logic of the game, lead and organize the entire course of the experience of the players involved, bringing about a unique collective experience, commonly portrayed by practitioners as exciting and overwhelming. What characterizes such experience? How is it provided by such games? What is its basic structure? These are some of the fundamental questions dealt with by this article.

\section{ACTION ET EXPÉRIENCE DANS LES SPORTS D'ÉQUIPE}

\section{Eduardo Fernandes Nazareth}

Mots-clés: Phénoménologie; Jeu; Sport ; Expérience; Pratique.

Le but de ce travail est de comprendre la constitution de l'expérience dans les jeux de sports collectifs, tels le football, le basket-ball, le volley-ball, le handball, d'entre autres. Une telle expérience est déterminée par le cours de l'action collective requise et autorisée par la forme du défi qui est géré. Des caractéristiques telles la création d'objectifs à atteindre contre une autre équipe, selon la logique d'une même action collective soumise à la logique de jeu, conduisent et ordonnent tout le cours de l'expérience des joueurs, provoquant une expérience collective singulière, communément décrite par les sportifs comme excitante et captivante. Qu'est-ce qui caractérise cette expérience? De quelle façon les ces jeux les proportionnent? Quelle est leur structure fondamentale? Voici les principales questions posées par cet article. 